TAO, Vol. 14, No. 2, 241-247, June 2003

NOTES AND CORRESPONDENCE

\title{
Segmented Faulting Process of Chelungpu Thrust: Implication of SAR Interferograms
}

\author{
Chien-Chih Chen ${ }^{1, *}$, Chung-Pai Chang ${ }^{2}$, and Kun-Shan Chen ${ }^{2}$
}

(Manuscript received 14 June 2002, in final form 10 March 2003)

\begin{abstract}
SAR interferograms have successfully determined the detailed coseismic displacements in the footwall block of the Chelungpu fault during the $\mathrm{Mw}$ 7.6 Chi-Chi earthquake in Taiwan on September 21, 1999 (local time). Based on the 3D dislocation model of faults, we infer the preliminary rupturing behavior - a segmented rupturing process - of the Chelungpu thrust from recent SAR interferograms. A key argument controlling the rupture of the Chelungpu thrust may be the recognized segments with different sliding depths of Chinshui Shale.
\end{abstract}

(Key words: SAR interferogram, Chi-Chi earthquake, Dislocation model, Segmented rupturing)

\section{INTRODUCTION}

In recent years, Interferometric Synthetic Aperture Radar (InSAR) has been widely applied to DTM (Digital Terrain Model) generation and land-cover change detection. Radar interferometry is a technique for extracting surface information of the Earth by using the phase content of the radar signal as an additional information source derived from the complex radar data. The use of InSAR for monitoring earth deformation process has received considerable attention, because of its great potential for mapping the movement associated with large earthquakes and other important geological events (e.g., Massonnet et al. 1994; Vadon and Sigmundsson 1997; Wicks et al. 1998; Chang et al. 2002). Compared with conventional mapping techniques, SAR interferometry can satisfy the requirements of global coverage and sophisticated image analysis of InSAR implements high spatial resolution and height accuracy simultaneously.

\footnotetext{
1 Institute of Geophysics, National Central University, Chungli, Taiwan 320, ROC

${ }^{2}$ Center for Space and Remote Sensing Research, National Central University, Chungli, Taiwan 320, ROC

* Corresponding author address: Prof. Chien-chih Chen, Institute of Geophysics, National Central University, Chungli, Taiwan, ROC; E-mail: s123@sal.gep.ncu.edu.tw
} 
This study attempts to undertake numerical modeling of the crustal deformation induced by the Chi-Chi earthquake in Taiwan, via the deformation data obtained by the InSAR technique. Theoretical deformation model simulates topometric variations at the surface and can be used to address the underlying geological processes, for instance, the fault rupturing during a seismic event or the fluid motions beneath the earth. A Mogi model, assuming that crustal deformation is caused by a hydrostatic-pressure change in a spherical source, is particularly useful in studies of crustal fluid dynamics, while dislocation model of faulting is usually used to simulate the coseismic deformation induced by a quake. We have undertaken in this study the preliminary 3D dislocation modeling (Thomas 1993) for InSAR deformation patterns of the Chi-Chi earthquake.

\section{SAR INTERFEROGRAMS OF THE CHI-CHI EARTHQUAKE}

With the aim of detecting deformation linked to the Chi-Chi earthquake, we apply radar interferometry, using SAR images acquired from the European Remote Sensing 2 (ERS2) satellite of the European Space Agency (ESA). The studied area is covered by one ERS2-SAR scene (descending orbit, track 232, frame 3123). The phase difference between two such images acquired at different times creates an interference (fringe) pattern called an interferogram (Massonnet and Feigl 1998). The interferograms show the change in range from ground to satellite, that is, the component of the displacement vector which points toward the satellite. Between two fringes of the same color (a phase variation of $2 \pi$ radians), there is $28 \mathrm{~mm}$ of range change for ERS2. Such an interferogram records crustal deformation during the time interval between the acquisitions of the two images.

In this study, we use the two-pass approach implemented by the GAMA ${ }^{\oplus}$ software. The parameters of scenes that we used in our interferometric analysis are listed in Table 1 . In the resulting interferograms, the effects of topography were removed by using the Taiwanese digital elevation model (DEM of Taiwan Forestry Bureau) with a grid interval of 40 by $40 \mathrm{~m}$ and metric average elevation accuracy retrieved from 1:5,000 topographic maps. Since the details of this technique have been described elsewhere, we restrict our discussion to interpret the interferogram in terms of crustal deformation.

The interferogram shown in Fig. 1 reveals a smoothed semi-elliptical pattern of shortening with a progressive increase from the west coast to the east after the Chi-Chi event. The maximum shortening in our unwrapped InSAR result is about $26 \mathrm{~cm}$, which occurs around the

Table 1. Parameters of ERS2-SAR data used in this study. Date of acquisition, interval time, vertical baseline offset $\left(B_{\perp}\right)$, parallel baseline offset $\left(B_{/ /}\right)$, and period are shown.

\begin{tabular}{|c|c|c|c|c|}
\hline Master orbit & Slave orbit & Time (day) & $\mathrm{B}_{\perp}(\mathrm{m})$ & $\mathrm{B}_{/ /}(\mathrm{m})$ \\
\hline $1999 / 10 / 28$ & $1999 / 05 / 06$ & 175 & 6 & 37 \\
\hline
\end{tabular}


central segment of the Chelungpu fault. The poor interferometric result on the hanging wall side of the Chelungpu fault was due to two principal causes, which may have acted together. The first cause involves the dense vegetation. East of the Chelungpu fault, hills and mountains are covered by dense forest and fruit trees, so from the C-band SAR it is difficult to detect the possible ground displacement. The second cause is that the amount of displacement at hanging wall is too large in the Chi-Chi event, about $5 \mathrm{~m}$ in general after previous field studies (Lee et al. 2001). The C-band SAR allows measurement of movements in the centimeter scale; the interferometric fringes are too complex to be distinguished when the vertical displacement is too large. Moreover, the coherence of radar image is almost lost in this case, making the detection very difficult.

Because the effect of flexural deformation decreases and vanishes from the near-fault area to the far fault area, the tectonic deformation in the footwall block of the Chelungpu fault, after InSAR result, is in good agreement with that predicted by the elastic rebound theory in the lower plate beneath a major thrust (Chang et al. 2002). It is, moreover, particularly interesting that some detailed concentric fringes are present around the neighborhoods of the Chelungpu fault in the SAR interferograms, as indicated by A, B and C in Fig. 1. Concentric fringe patterns will be modeled in this study and their tectonic implication will be discussed below.

\subsection{DISLOCATION MODEL}

To model the surface deformation induced by the Chi-Chi earthquake, as observed in the SAR interferograms, we have used a computer program Poly3D (Thomas 1993) in this study. Poly3D is a $\mathrm{C}$ language computer program that calculates the displacements, strains and stresses induced in an elastic whole- or half-space by planar, polygonal-shaped elements of the displacement discontinuity, such as geological joints or faults. Dislocations of varying shapes may be combined to yield complex three-dimensional surfaces well suited for modeling faults in the earth's crust. The algebraic expressions for the elastic fields around a polygonal element are derived by superposing the solution for an angular dislocation in an elastic half-space (Thomas 1993). Detailed explanation of mathematical expressions and the coding algorithm of Poly3D can be found in Thomas (1993).

Figures 2, 3 and 4 show results obtained from Poly3D of modeling the displacement and calculated interferometric fringe patterns in the footwalls of a single fault (Fig. 2) and three continuous but segmented faults (Figs. 3 and 4) with different slipping depths. The model parameters are given in Table 2. Here we emphasize the concentric fringe patterns as displayed in the aforementioned SAR interferograms of the Chi-Chi earthquake (Fig. 1). As it can be seen in Fig. 2, the concentric fringe patterns will appear only at the both ends of a single fault, where they correspond to the uplift and subsidence behaviors at these two ends respectively. Consequently, when several pairs of such concentric fringe patterns are found in a single event like the deformation of Chi-Chi earthquake (Fig. 1), they then may indicate an important character of the segmented faulting process. We have modeled the deformation pattern of the segmented faulting process. As shown in Figs. 3 and 4, a long and segmented 


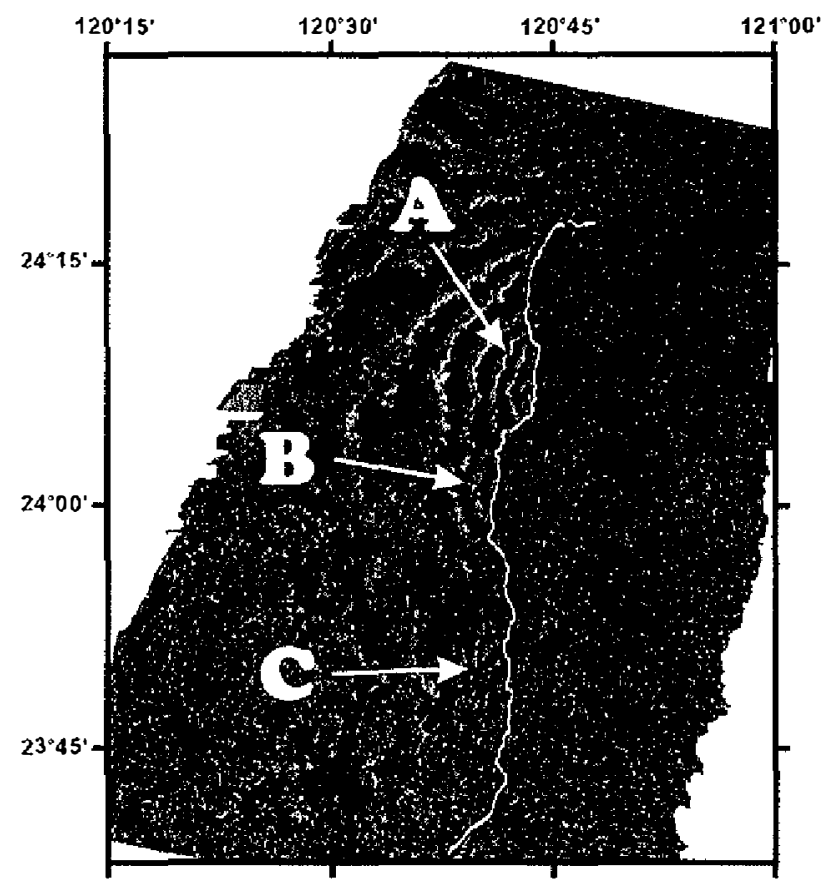

Fig. 1. An example of SAR interferogram with the radar image pair of (6 May 1999 - 28 October 1999) in the footwall block of the Chelungpu thrust (Chang et al. 2002). It is noted that some detailed concentric fringes are present in the neighborhoods of the Chelungpu fault, as indicated by A, B and C. Each fringe corresponds to a deformation displacement of about $2.8 \mathrm{~cm}$.
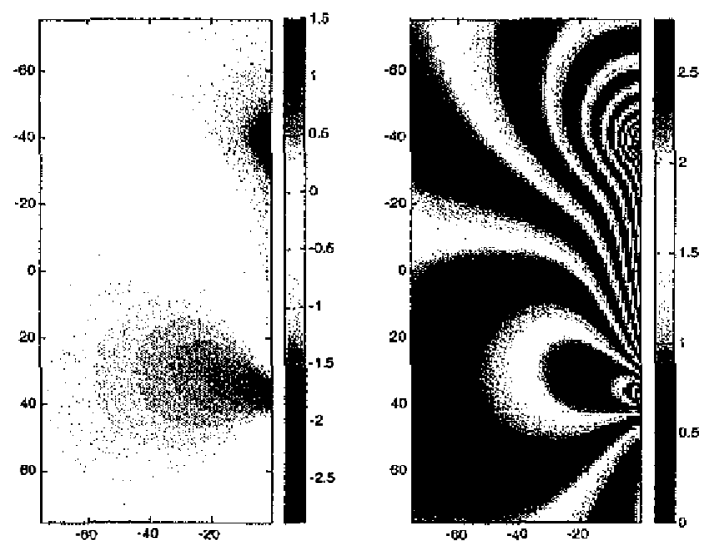

Fig. 2. Numerical modeling of 3D dislocation theory for the displacement (left) and interferometric fringe (right) patterns in the footwall of a single fault. Note that the concentric fringes only appear at the both ends of the fault. 

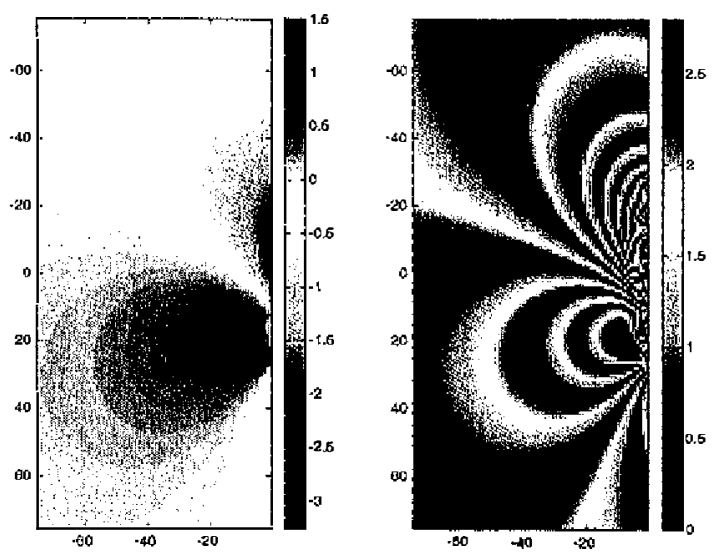

Fig. 3. Numerical modeling of 3D dislocation theory for the displacement (left) and interferometric fringe (right) patterns in the footwall of three segmented faults with different depths. Note that two concentric fringe patterns (right), corresponding to two local minima in the displacement (left), appear between 0 and $20 \mathrm{~km}$ along the vertical $y$-axis.
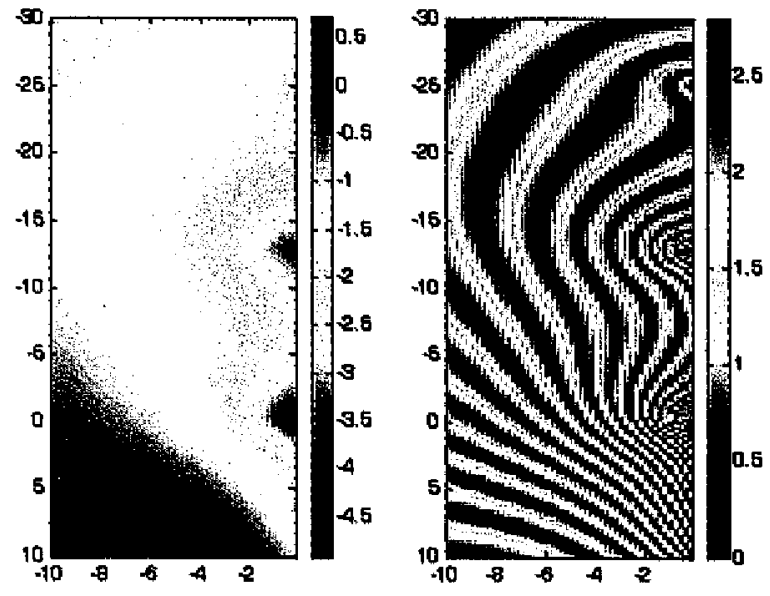

Fig. 4. A zoom-in picture of the displacement (left) and interferometric fringe (right) patterns in the neighborhoods of the faults in Fig. 3. 
Table 2. Fault parameters used in Poly3D.

\begin{tabular}{|c|c|c|c|c|c|c|}
\hline \multicolumn{2}{|c|}{} & $\begin{array}{c}\text { Strike due } \\
\text { north } \\
\text { (degree) }\end{array}$ & $\begin{array}{c}\text { Dip angle } \\
(\text { degree) }\end{array}$ & $\begin{array}{c}\text { Depth of } \\
\text { the } \\
\text { bottom } \\
(\mathrm{km})\end{array}$ & $\begin{array}{c}\text { Length/Width } \\
(\mathrm{km})\end{array}$ & $\begin{array}{c}\text { Strike-slip/Dip-slip } \\
(\mathrm{m})\end{array}$ \\
\hline \multicolumn{2}{|c|}{ Single fault in Figure 2 } & 0 & 28 & 14.1 & $75 / 30$ & $3 / 3$ \\
\hline \multirow{2}{*}{$\begin{array}{c}\text { Segmented } \\
\text { faults in } \\
\text { Figures 3 \& 4 }\end{array}$} & Segment I & 0 & 28 & 14.1 & $25 / 30$ & $1 / 1$ \\
\cline { 2 - 7 } & Segment II & 0 & 28 & 9.4 & $25 / 20$ & $3 / 3$ \\
\hline
\end{tabular}

fault with different slipping-depth segments indeed produces more concentric fringe patterns along the surficial fault trace.

Very recently, Lee et al. (2001) and Rubin et al. (2001) identified several segments along the Chelungpu thrust of the 1999 Chi-Chi rupture, based on the motion discontinuities in the surficial fault trace in Rubin et al. (2001) and the morphology of Chinshui Shale in Lee et al. (2001). According to our preliminary modeling, SAR interferogram obtained in Chang et al. (2002) is thereby in good agreement with the conclusion of the segmented structural character of the 1999 Chi-Chi rupture (Lee et al. 2001).

\section{CONCLUSION AND TASKS IN THE FUTURE}

SAR interferometry has successfully revealed the detailed coseismic displacements in the footwall block of the Chelungpu thrust during the Chi-Chi earthquake. Based on the deformation patterns of SAR interferograms obtained in Chang et al. (2002) and the preliminary 3D dislocation model of faults implemented in this study, we have suggested a segmented rupturing behavior of the Chelungpu thrust accordingly. A key argument controlling the rupturing of the Chelungpu thrust may be the recognized fault segments with different sliding depths of Chinshui Shale, as proposed in Lee et al. (2001), instead of the "one-fault" or "three-fault" models proposed previously in Johnson et al. (2001).

It is noticed that we do not intend to invert completely the observed SAR interferograms in this preliminary study, but draw an important feature regarding the Chi-Chi earthquake, the segmented faulting process. A further inversion algorithm of $3 \mathrm{D}$ dislocation fault model is still under construction and is going to be completed in the near future. We believe that the detailed patterns of SAR interferograms could be better inverted and the clearer faulting behavior concerned with the Chelungpu thrusting could be addressed after completion of our coding work.

Acknowledgements Authors are indebted to Prof. T. T. Yu and one anonymous referee for reviewing our earlier manuscript. This work was supported by research grants NSC 90-2116- 
M-008-007 and NSC-91-2116-M-008-011 from National Sciences Council, ROC.

\section{REFERENCES}

Chang, C. P., C. T. Wang, T. Y. Chang, K. S. Chen, L. S. Liang, E. Pathier, and J. Angelier, 2002: Application of SAR interferometry to a large thrusting deformation, The 1999 $\mathrm{Mw}=7.6$ Chichi earthquake(Central Taiwan). AGU 2002 Fall Meeting, San Francisco, California, T61B-1267.

Johnson, K. M., Y. J. Hsu, P. Segall, and S. B. Yu, 2001: Fault geometry and slip distribution of the 1999 Chi-Chi, Taiwan earthquake imaged from inversion of GPS data. Geophysical Research Letters, 28, 2285-2288.

Lee, Y. H., S. T. Lu, and T. S. Shih, 2001: Segmented structural character of the Chelungpu thrust. Report to the Central Geological Survey, MOEA, ROC.

Massonnet, D., K. Feigl, M. Rossi, and F. Adragna, 1994: Radar interferometric mapping of deformation in the year after the Landers earthquake. Nature, 369, 227-230.

Rubin, C. M., K. Sieh, Y. G. Chen, J. C. Lee, H. C. Chu, R. Yeats, K. Mueller, and Y. C. Chan, 2001: Surface rupture and behavior of thrust faults probed in Taiwan. Eos Trans. Am. Geophys. Union, 82, 565-569.

Thomas, A. L., 1993: Poly3D: A Three-Dimensional, Polygonal Element, Displacement Discontinuity Boundary Element Computer Program with Applications to Fractures, Faults, and Cavities in the Earth's Crust. M.S. Thesis of Stanford University, Stanford, CA, USA.

Vadon, H., and F. Sigmundsson, 1997: Crustal deformation from 1992 to 1995 at the MidAtlantic ridge, southwest Iceland, mapped by satellite radar interferometry. Science, 275, 193-197.

Wicks, C., Jr., W. Thatcher, and D. Dzurisin, 1998: Migration of fluids beneath Yellowstone caldera inferred from satellite radar interferometry. Science, 282, 458-462. 